\title{
Influence of cation substitution on phase transition and optical absorption edge in $\mathrm{Cu}_{6}\left(\mathrm{P}_{1-\mathrm{x}} A s_{\mathrm{x}}\right) \mathrm{S}_{5} \mathrm{I}$ mixed crystals
}

\author{
I.P. Studenyak ${ }^{1}$, M. Kranjčec ${ }^{2}$, M.I. Kayla ${ }^{1}$, V.Yu. Izai ${ }^{1}$, A.F. Orliukas ${ }^{3}$ \\ ${ }^{1}$ Uzhhorod National University, Physics Faculty, \\ 46, Pidhirna str., 88000 Uzhhorod, Ukraine \\ ${ }^{2}$ University of Zagreb, Geotechnical Faculty, \\ Hallerova Aleja 7, 42000 Varaždin, Croatia \\ ${ }^{3}$ Vilnius University, Physics Faculty, \\ Sauletekio al. 9, LT-10222 Vilnius, Lithuania \\ E-mail:studenyak@dr.com
}

\begin{abstract}
Cu}_{6}\left(\mathrm{P}_{1-\mathrm{x}} \mathrm{As}_{\mathrm{x}}\right) \mathrm{S}_{5} \mathrm{I}$ mixed crystals were grown using chemical vapour transport. Temperature isoabsorption investigations of optical absorption edge enable to reveal anomalies typical for the first- and second-order phase transitions as well as to construct the $x, T$-diagram. The spectrometric measurements of the optical absorption edge in $\mathrm{Cu}_{6}\left(\mathrm{P}_{1-\mathrm{x}} \mathrm{As}_{\mathrm{X}}\right) \mathrm{S}_{5} \mathrm{I}$ superionic mixed crystals were carried out within the temperature range $77-320 \mathrm{~K}$. The influence of temperature and composition on optical absorption edge, parameters of exciton-phonon interaction as well as ordering-disordering processes in $\mathrm{Cu}_{6}\left(\mathrm{P}_{1-\mathrm{x}} \mathrm{As}_{\mathrm{x}}\right) \mathrm{S}_{5} \mathrm{I}$ superionic mixed crystals have been studied.
\end{abstract}

Keywords: mixed crystals, absorption edge, Urbach rule, exciton-phonon interaction.

Manuscript received 16.01.13; revised version received 28.02.13; accepted for publication 19.03.13; published online 25.06.13.

\section{Introduction}

$\mathrm{Cu}_{6} \mathrm{PS}_{5} \mathrm{I}$ and $\mathrm{Cu}_{6} \mathrm{AsS}_{5} \mathrm{I}$ crystals belong to compounds of the argyrodite structure [1-3]. It is well-known that argyrodite crystals are characterized by high ionic conductivity that determines the possibilities of their application in new devices for solid state ionics [4]. The main reasons and peculiarities of high ionic conductivity in materials of this type are studied in the works [1-3]. The $\mathrm{Cu}_{6} \mathrm{PS}_{5} \mathrm{I}$ crystal is the most intensely studied one among argyrodite-type superionic conductors.

At low temperatures, in the $\mathrm{Cu}_{6} \mathrm{PS}_{5} \mathrm{I}$ crystal two phase transitions (PTs) occur: (i) a structural secondorder PT at $T_{\mathrm{II}}=(269 \pm 2) \mathrm{K}$ which is accompanied by the symmetry change $F \overline{4} 3 m \rightarrow F \overline{4} 3 c$ and (ii) a superionic and ferroelastic first-order PT at $T_{\mathrm{I}}=(144 \pm 1) \mathrm{K}$ accompanied by the symmetry change $F \overline{4} 3 c \rightarrow C c$ $[5,6]$. Studies of the optical absorption edge in $\mathrm{Cu}_{6} \mathrm{PS}_{5} \mathrm{I}$ crystal have shown the existence of bound and free excitons at high absorption levels at temperatures below the first-order PT, which undergo the significant changes with the temperature increase [7,8]. At the transition into the superionic state not only the exciton structure changes, but also exponential parts appear at the longwave absorption edge. At $T>T_{\mathrm{I}}$, the temperature behaviour of the exponential parts of the absorption edge is described by the empirical Urbach rule $[7,8]$. 
In $\mathrm{Cu}_{6} \mathrm{AsS}_{5} \mathrm{I}$ crystal, from the isoabsorption studies two low-temperature PTs were observed: first-order PT at $T_{\mathrm{I}}=(153 \pm 1) \mathrm{K}$ and second-order PT at $T_{\mathrm{II}}=260 \ldots .280 \mathrm{~K}$ [9]. At low temperatures and high absorption levels, an excitonic absorption band is observed in the range of direct optical transitions, which shifts with temperature towards higher energies, broadens and is fully smeared out at the first-order PT temperature. At $T>T_{\mathrm{I}}$, the absorption edge has an exponential shape, and a characteristic Urbach bundle is observed.

In Ref. [10], the complex electrical conductivity of $\mathrm{Cu}_{6} \mathrm{P}_{1-\mathrm{x}} \mathrm{As}_{\mathrm{X}} \mathrm{S}_{5} \mathrm{I}$ composites was measured within the temperature interval 100 to $300 \mathrm{~K}$ and frequency range $10 \mathrm{~Hz}$ to $1.2 \mathrm{GHz}$. On the frequency dependences of electrical conductivity, for $\mathrm{Cu}_{6} \mathrm{P}_{1-\mathrm{x}} \mathrm{As}_{\mathrm{x}} \mathrm{S}_{5} \mathrm{I}$ composites two dispersion ranges caused by the ion transport in the grain boundary and the bulk, are observed: (i) the lowfrequency parts of the spectra correspond to the grain boundary processes, (ii) the high-frequency parts of the spectra can be attributed to the relaxation in the bulk. At $T=300 \mathrm{~K}$ and frequency $10^{3} \mathrm{~Hz}$, the electrical conductivity of $\mathrm{Cu}_{6} \mathrm{AsS}_{5} \mathrm{I}$ single crystal is $\sigma^{\prime}=1.4 \cdot 10^{-4} \mathrm{~S} / \mathrm{m}$, while in $\mathrm{Cu}_{6} \mathrm{AsS}_{5} \mathrm{I}$ composite it is $\sigma^{\prime}=4.5 \cdot 10^{-5} \mathrm{~S} / \mathrm{m}$. It is shown that $\mathrm{P} \rightarrow \mathrm{As}$ cationic substitution results in a nonlinear decrease of the electrical conductivity by more than two orders of magnitude [10].

The present paper is aimed at determination of PT temperatures by using isoabsorption investigations, construction of the $x, T$-diagram and spectrometric studies of optical absorption edge in $\mathrm{Cu}_{6}\left(\mathrm{P}_{1-\mathrm{x}} \mathrm{As}_{\mathrm{X}}\right) \mathrm{S}_{5} \mathrm{I}$ superionic mixed crystals. Besides, in this paper the influence of temperature and composition on optical absorption edge, parameters of exciton-phonon interaction as well as ordering-disordering processes in $\mathrm{Cu}_{6}\left(\mathrm{P}_{1-\mathrm{x}} \mathrm{As}_{\mathrm{x}}\right) \mathrm{S}_{5} \mathrm{I}$ superionic mixed crystals are studied.

\section{Experimental}

High-purity $\mathrm{Cu}, \mathrm{P}, \mathrm{S}, \mathrm{As}_{2} \mathrm{~S}_{3}$ and $\mathrm{CuI}$ were used to synthesize $\mathrm{Cu}_{6}\left(\mathrm{P}_{1-\mathrm{x}} \mathrm{As}_{\mathrm{X}}\right) \mathrm{S}_{5} \mathrm{I}$ crystals. These mixed crystals were grown using chemical vapour transport. $\mathrm{CuI}$ in an amount of $10 \ldots 20 \mathrm{mg}$ per $1 \mathrm{~cm}^{3}$ of the ampoule free volume was used as a transport agent. The temperatures of the evaporation zone and the crystallization one were kept at $893 \ldots 923 \mathrm{~K}$ and $853 \ldots 873 \mathrm{~K}$, respectively. Single crystals were grown in the shape of $5 \times 3 \times 2 \mathrm{~mm}$-size plane-parallel plates or distorted tetrahedra.

Isoabsorption and spectrometric studies of optical absorption edge were carried out within the temperature range 77 to $320 \mathrm{~K}$ using a LOMO MDR-3 grating monochromator. For low temperature studies, an UTREX cryostat was used, the stability and accuracy of the temperature measurements was $\pm 0.5 \mathrm{~K}$. The absorption coefficient value $\alpha$ was calculated being based on the experimental values of the transmission coefficient $T_{t r}$ and reflectivity $r$ using the known formula

$\alpha=\frac{1}{d} \ln \left[\frac{(1-r)^{2}+\sqrt{(1-r)^{4}+4 T_{t r}^{2} r^{2}}}{2 T_{t r}}\right]$,

where $d$ is the sample thickness. The relative error in the absorption coefficient determination $\Delta \alpha / \alpha$ did not exceed $10 \%$ at $0.3 \leq \alpha d \leq 3$ [8]. The isoabsorption studies of the optical absorption edge consisted in the determination of the energy position of the optical absorption edge $E_{g}^{\alpha}(T)$ at fixed values of the absorption coefficient $\alpha$ and temperature $T$.

\section{Results and discussion}

Temperature isoabsorption studies of the optical absorption edge enabled to investigate the influence of cation substitution of $\mathrm{P}$ atoms by As atoms on PT temperatures in $\mathrm{Cu}_{6}\left(\mathrm{P}_{1-\mathrm{x}} \mathrm{As}_{\mathrm{x}}\right) \mathrm{S}_{5} \mathrm{I}$ mixed crystals. The typical temperature dependence of spectral position of absorption edge $E_{g}^{\alpha}$ for $\mathrm{Cu}_{6}\left(\mathrm{P}_{0.4} \mathrm{As}_{0.6}\right) \mathrm{S}_{5}$ I mixed crystal is presented in Fig. 1. Similar to the single crystals $\mathrm{Cu}_{6} \mathrm{PS}_{5} \mathrm{I}$ [11] and $\mathrm{Cu}_{6} \mathrm{AsS}_{5} \mathrm{I}$ [9], several intervals can be distinguished in the temperature dependence of $E_{g}^{\alpha}$ for $\mathrm{Cu}_{6}\left(\mathrm{P}_{0.4} \mathrm{As}_{0.6}\right) \mathrm{S}_{5} \mathrm{I}$ mixed crystal (Fig. 1): within the temperature range $77 \ldots 151 \mathrm{~K} E_{g}^{\alpha}$ grows monotonically, within the temperature interval $151 \ldots 158 \mathrm{~K}$ a stepwise change of $E_{g}^{\alpha}$ is observed, $d E_{g}^{\alpha} / d T>0$, at $T>158 \mathrm{~K}$ a nonlinear decrease of $E_{g}^{\alpha}$ is observed, at $(280 \pm 2) \mathrm{K}$ the slope of $E_{g}^{\alpha}(T)$ dependence is slightly changed. The revealed stepwise anomaly of $E_{g}^{\alpha}$ at $T_{\mathrm{I}}=(154 \pm 1) \mathrm{K}$ (in

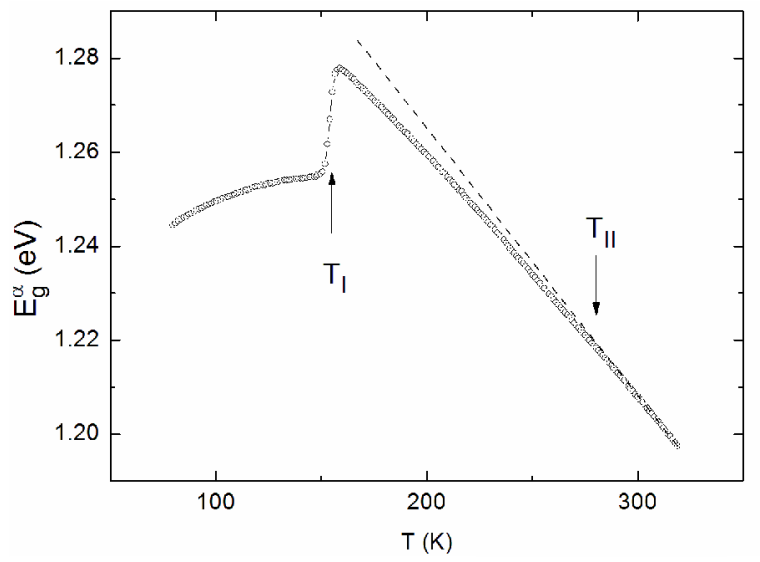

Fig. 1. Temperature dependence of $E_{g}^{\alpha}\left(\alpha=250 \mathrm{~cm}^{-1}\right)$ for $\mathrm{Cu}_{6}\left(\mathrm{P}_{0.4} \mathrm{As}_{0.6}\right) \mathrm{S}_{5} \mathrm{I}$ mixed crystal, obtained in the heating mode. 
the heating mode) and temperature hysteresis $(6 \mathrm{~K})$ in $\mathrm{Cu}_{6}\left(\mathrm{P}_{0.4} \mathrm{As}_{0.6}\right) \mathrm{S}_{5} \mathrm{I}$ crystal is characteristic for the firstorder $\mathrm{PT}$, while a feature in the temperature range $T_{\mathrm{II}}=$ $(280 \pm 2) \mathrm{K}$ is typical for the second-order PT. Analogous isoabsorption dependences are observed for other $\mathrm{Cu}_{6}\left(\mathrm{P}_{1-\mathrm{x}} \mathrm{As}_{\mathrm{X}}\right) \mathrm{S}_{5} \mathrm{I}$ mixed crystals. On their base, the PT temperatures were determined, as well as the $x, T$ diagram was constructed, the last one contains two lines of the first-oder and the second-order PTs (Fig. 2). It is shown that increase of As atoms content in $\mathrm{Cu}_{6}\left(\mathrm{P}_{1-\mathrm{x}} \mathrm{As}_{\mathrm{X}}\right) \mathrm{S}_{5} \mathrm{I}$ mixed crystals leads to the monotonous increase in PT temperatures, however, small peculiarity at $x=0.8$ is observed.

The studies of optical absorption edge in $\mathrm{Cu}_{6}\left(\mathrm{P}_{1-\mathrm{x}} \mathrm{As}_{\mathrm{X}}\right) \mathrm{S}_{5} \mathrm{I}$ mixed crystals were carried out in the temperature range of $T=77-320 \mathrm{~K}$. Fig. 3 illustrates the typical Urbach "bundle" for $\mathrm{Cu}_{6}\left(\mathrm{P}_{0.4} \mathrm{As}_{0.6}\right) \mathrm{S}_{5} \mathrm{I}$ mixed crystal. It is shown that in the superionic phase the optical absorption edge for all $\mathrm{Cu}_{6}\left(\mathrm{P}_{1-\mathrm{x}} \mathrm{As}_{\mathrm{X}}\right) \mathrm{S}_{5} \mathrm{I}$ mixed crystals is described by the well known relation [12]:

$\alpha(h v, T)=\alpha_{0} \cdot \exp \left[\frac{\sigma\left(h v-E_{0}\right)}{k T}\right]$,

where $\sigma=k T / E_{\mathrm{U}}$ is the steepness parameter of the absorption edge, $E_{\mathrm{U}}$ is the Urbach energy or the energy width of exponential absorption edge, $\alpha_{0}$ and $E_{0}$ are the coordinates of the convergence point of the Urbach bundle. Parameters $\alpha_{0}$ and $E_{0}$ for $\mathrm{Cu}_{6}\left(\mathrm{P}_{1-\mathrm{x}} \mathrm{As}_{\mathrm{X}}\right) \mathrm{S}_{5} \mathrm{I}$ mixed crystals were shown in Table. Parameters of the exciton-phonon interaction (EPI) $\sigma_{0}$ and $\hbar \omega_{p}$ were estimated from the temperature dependences of the absorption edge slope parameter $\sigma$ (see insets in Fig. 3 ) by the Mahr equation [13]:
$\sigma(T)=\sigma_{0} \cdot\left(\frac{2 k T}{\hbar \omega_{p}}\right) \cdot \operatorname{th}\left(\frac{\hbar \omega_{p}}{2 k T}\right)$,

where $\hbar \omega_{p}$ is the effective average phonon energy in a single-oscillator model, which describes the EPI; $\sigma_{0}$ is the parameter related to the EPI constant $g$ by the relation $\sigma_{0}=2 / 3 g$. The parameters $\hbar \omega_{p}$ and $\sigma_{0}$ for $\mathrm{Cu}_{6}\left(\mathrm{P}_{1-\mathrm{X}} \mathrm{As}_{\mathrm{X}}\right) \mathrm{S}_{5} \mathrm{I}$ mixed crystals are listed in Table. It is shown that $\mathrm{Cu}_{6}\left(\mathrm{P}_{1-\mathrm{X}} \mathrm{As}_{\mathrm{X}}\right) \mathrm{S}_{5} \mathrm{I}$ mixed crystals have the parameter $\sigma_{0}>1$, which is an evidence of a weak EPI. When As atoms content increases in $\mathrm{Cu}_{6}\left(\mathrm{P}_{1-\mathrm{x}} \mathrm{As}_{\mathrm{X}}\right) \mathrm{S}_{5} \mathrm{I}$ mixed crystals, the EPI weakening (nonlinear increase of $\sigma_{0}$ parameter) and the nonlinear decrease of effective phonon energy are observed (Table).

From the analysis of optical absorption edge in $\mathrm{Cu}_{6}\left(\mathrm{P}_{1-\mathrm{x}} \mathrm{As}_{\mathrm{x}}\right) \mathrm{S}_{5} \mathrm{I}$ mixed crystals, the temperature dependences of the optical pseudogap $E_{g}^{*}\left(E_{g}^{*}\right.$ is the absorption edge energy position at the fixed value of the absorption coefficient $\alpha=10^{3} \mathrm{~cm}^{-1}$ ) and Urbach energy $E_{\mathrm{U}}$ were constructed. Fig. 4 presents typical dependences $E_{g}^{*}(T)$ and $E_{\mathrm{U}}(T)$ for $\mathrm{Cu}_{6}\left(\mathrm{P}_{0.4} \mathrm{As}_{0.6}\right) \mathrm{S}_{5} \mathrm{I}$ mixed crystal. It is shown that the temperature dependences of $E_{g}^{*}$ and $E_{\mathrm{U}}$ are described within the framework of Einstein's model by equations [14, 15]:

$$
\begin{aligned}
& E_{g}^{*}(T)=E_{g}^{*}(0)-S_{g}^{*} k \theta_{\mathrm{E}}\left[\frac{1}{\exp \left(\theta_{\mathrm{E}} / T\right)-1}\right], \\
& \left(E_{\mathrm{U}}\right)=\left(E_{\mathrm{U}}\right)_{0}+\left(E_{\mathrm{U}}\right)_{1}\left[\frac{1}{\exp \left(\theta_{\mathrm{E}} / T\right)-1}\right],
\end{aligned}
$$

Table. Parameters of the Urbach absorption edge and the EPI for $\mathrm{Cu}_{6}\left(\mathrm{P}_{1-\mathrm{x}} A s_{\mathrm{x}}\right) \mathrm{S}_{5} \mathrm{I}$ mixed crystals.

\begin{tabular}{|l|c|c|c|c|c|c|}
\hline Crystal & $\mathrm{Cu}_{6} \mathrm{PS}_{5} \mathrm{I}$ & $x=0.2$ & $x=0.4$ & $x=0.6$ & $x=0.8$ & $\mathrm{Cu}_{6} \mathrm{AsS}_{5} \mathrm{I}$ \\
\hline$\alpha_{0}\left(\mathrm{~cm}^{-1}\right)$ & $4.7 \cdot 10^{5}$ & $6.4 \cdot 10^{5}$ & $7.2 \cdot 10^{5}$ & $7.8 \cdot 10^{5}$ & $5.5 \cdot 10^{5}$ & $4.8 \cdot 10^{5}$ \\
\hline$E_{0}(\mathrm{eV})$ & 2.234 & 1.698 & 1.443 & 1.355 & 1.349 & 1.332 \\
\hline$E_{g}^{*}(300 \mathrm{~K})(\mathrm{eV})$ & 2.089 & 1.563 & 1.311 & 1.239 & 1.221 & 1.216 \\
\hline$E_{\mathrm{U}}(300 \mathrm{~K})(\mathrm{meV})$ & 23.7 & 20.6 & 18.6 & 17.9 & 19.9 & 19.0 \\
\hline$\sigma_{0}$ & 1.16 & 1.31 & 1.44 & 1.65 & 1.46 & 1.38 \\
\hline$\hbar \omega_{p}(\mathrm{meV})$ & 22.1 & 23.2 & 24.8 & 26.6 & 36.3 & 8.5 \\
\hline$\theta_{\mathrm{E}}(\mathrm{K})$ & 257 & 268 & 288 & 308 & 421 & 98 \\
\hline$\left(E_{\mathrm{U}}\right)_{0}(\mathrm{meV})$ & 9.6 & 9.1 & 8.5 & 7.8 & 9.6 & 2.9 \\
\hline$\left(E_{\mathrm{U}}\right)_{1}(\mathrm{meV})$ & 19.1 & 18.8 & 18.1 & 16.4 & 33.2 & 6.2 \\
\hline$E_{g}^{*}(0)(\mathrm{eV})$ & 2.170 & 1.643 & 1.405 & 1.316 & 1.279 & 1.328 \\
\hline$S_{g}^{*}$ & 4.98 & 4.96 & 4.95 & 4.97 & 4.93 & 5.06 \\
\hline
\end{tabular}


where $E_{g}^{*}(0)$ and $S_{g}^{*}$ are the optical pseudogap at $T=0 \mathrm{~K}$ and a dimensionless constant, respectively; $\left(E_{\mathrm{U}}\right)_{0}$ and $\left(E_{\mathrm{U}}\right)_{1}$ are constants; $\theta_{E}$ is the Einstein temperature corresponding to the average frequency of phonon excitations in a system of non-coupled oscillators. Similar temperatures dependences of $E_{g}^{*}$ and $E_{\mathrm{U}}$ for all other $\mathrm{Cu}_{6}\left(\mathrm{P}_{1-\mathrm{x}} \mathrm{As}_{\mathrm{x}}\right) \mathrm{S}_{5} \mathrm{I}$ mixed crystals are well described by the equations (4) and (5); the fitting parameters $E_{g}^{*}(0), S_{g}^{*},\left(E_{\mathrm{U}}\right)_{0},\left(E_{\mathrm{U}}\right)_{1}$ and $\theta_{E}$ are presented in Table.

Fig. 5 shows the compositional dependences of the optical pseudogap $E_{g}^{*}$ and Urbach energy $E_{\mathrm{U}}$ for $\mathrm{Cu}_{6}\left(\mathrm{P}_{1-\mathrm{x}} \mathrm{As}_{\mathrm{x}}\right) \mathrm{S}_{5} \mathrm{I}$ mixed crystals. It is revealed that, with increase in the content of As atoms in $\mathrm{Cu}_{6}\left(\mathrm{P}_{1-\mathrm{x}} \mathrm{As}_{\mathrm{x}}\right) \mathrm{S}_{5} \mathrm{I}$ mixed crystals, the optical pseudogap decreases nonlinearly. The Urbach energy has the tendency to decrease at $\mathrm{P} \rightarrow$ As substitution, however, the character of compositional behavior in this case is more complicated, because the small peculiarity at $x=0.8$ is observed.

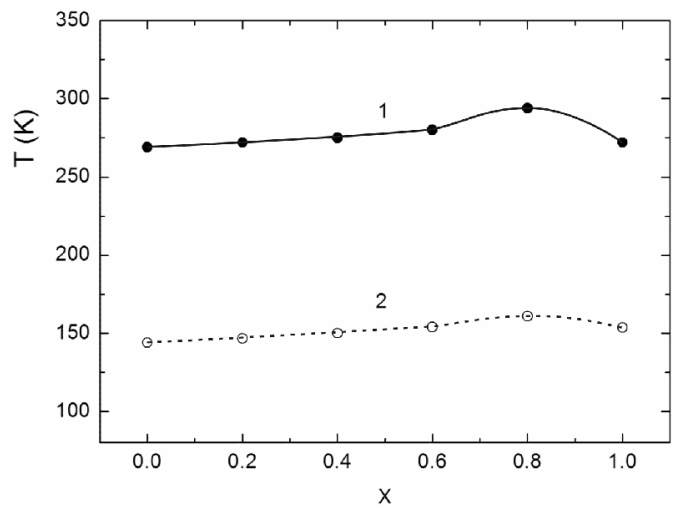

Fig. 2. Compositional dependences of the second-order (1) and the first-oder (2) PT temperatures for the $\mathrm{Cu}_{6}\left(\mathrm{P}_{1-\mathrm{x}} \mathrm{As}_{\mathrm{x}}\right) \mathrm{S}_{5} \mathrm{I}$ mixed crystal.

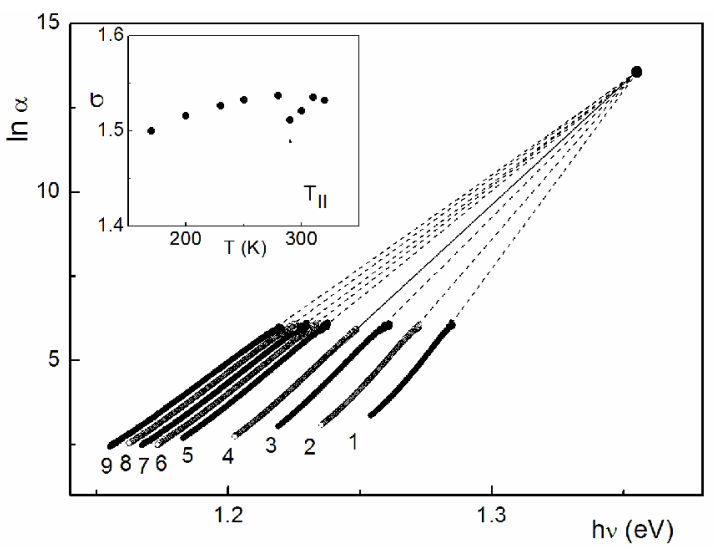

Fig. 3. Spectral dependences of the Urbach absorption edge for the $\mathrm{Cu}_{6}\left(\mathrm{P}_{0.4} \mathrm{As}_{0.6}\right) \mathrm{S}_{5} \mathrm{I}$ mixed crystal at various temperatures, $T(\mathrm{~K}): 1-170,2-200,3-230,4-250,5-280,6-290,7-$ $300,8-310,9-320$. The inset shows the temperature dependence of the slope parameter $\sigma$ for the absorption edge.

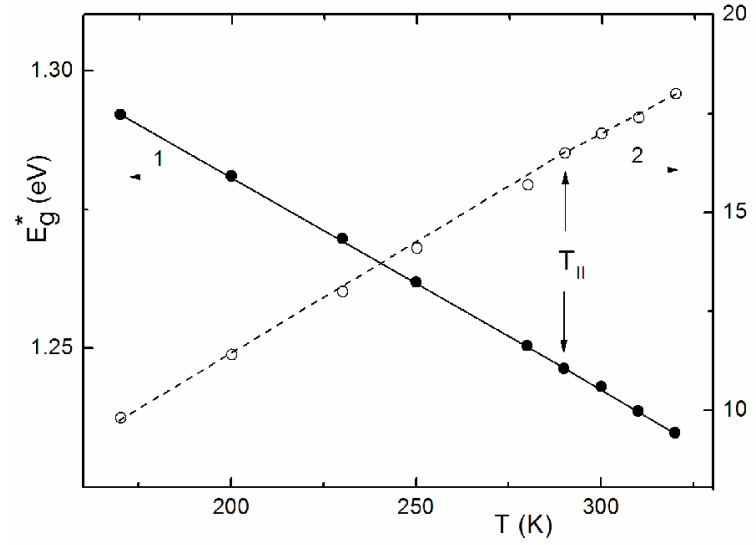

Fig. 4. Temperature dependences of the optical pseudogap $E_{g}^{*}(1)$ and Urbach energy $E_{\mathrm{U}}(2)$ for the $\mathrm{Cu}_{6}\left(\mathrm{P}_{0.4} \mathrm{As}_{0.6}\right) \mathrm{S}_{5} \mathrm{I}$ mixed crystal.

It is well known that the Urbach energy $E_{U}$ characterizes the degree of edge smearing due to different types of disordering in the crystal lattice. In $\mathrm{Cu}_{6}\left(\mathrm{P}_{1-\mathrm{x}} \mathrm{As}_{\mathrm{x}}\right) \mathrm{S}_{5} \mathrm{I}$ mixed crystals, besides the temperature (due to the lattice thermal vibrations) and structural (static and dynamical) disordering, typical for $\mathrm{Cu}_{6} \mathrm{PS}_{5} \mathrm{I}$ and $\mathrm{Cu}_{6} \mathrm{AsS}_{5} \mathrm{I}$ crystals, compositional disordering should be also revealed. According to [16], the influence of different types of disordering on the Urbach energy in mixed crystals is described by the relation

$E_{\mathrm{U}}=\left(E_{\mathrm{U}}\right)_{X}+\left(E_{\mathrm{U}}\right)_{T}+\left(E_{\mathrm{U}}\right)_{C}=$

$=\left(E_{\mathrm{U}}\right)_{X, C}+\left(E_{\mathrm{U}}\right)_{T}$,

where $\left(E_{\mathrm{U}}\right)_{X},\left(E_{\mathrm{U}}\right)_{T}$ and $\left(E_{\mathrm{U}}\right)_{C}$ are the contributions of structural, temperature and compositional disordering to the Urbach energy $E_{\mathrm{U}}$, respectively. Comparison of two equations (5) and (6) evidences that $\left(E_{\mathrm{U}}\right)_{\mathrm{X}, \mathrm{C}} \equiv\left(E_{\mathrm{U}}\right)_{0}$ and $\left(E_{\mathrm{U}}\right)_{T} \equiv\left(E_{\mathrm{U}}\right)_{1} /\left(\exp \left(\theta_{\mathrm{E}} / T\right)-1\right)$. Thus, the contributions of temperature-independent $\left(E_{\mathrm{U}}\right)_{X, C}$ (structural and compositional) and temperaturedependent $\left(E_{\mathrm{U}}\right)_{T}$ disordering were separated. Their compositional dependences are presented in Fig. 6. It should be noted that the $\mathrm{P} \rightarrow$ As substitution leads to the decrease of the absolute value of the contribution of structural disordering into the Urbach energy by more than 3 times, the latter corresponds to decrease of the relative value inherent to the contribution of structural disordering into the Urbach energy from 41 down to $15 \%$. In approximation of linear compositional variation of the contribution of structural disordering into the Urbach energy, one can separate from $\left(E_{\mathrm{U}}\right)_{X, C}$ the contribution of compositional disordering $\left(E_{\mathrm{U}}\right)_{C}$, which reaches the maximum value at $x=0.8$. This fact well correlates with the peculiarity on $x, T$-diagram at the same $x$ value. 


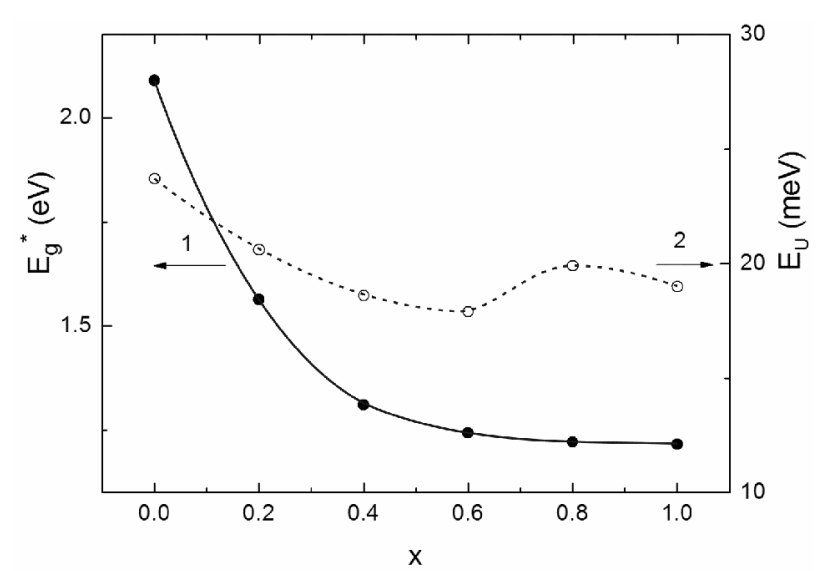

Fig. 5. Compositional dependences of the optical pseudogap $E_{g}^{*}(1)$ and Urbach energy $E_{\mathrm{U}}(2)$ for $\mathrm{Cu}_{6}\left(\mathrm{P}_{1-\mathrm{x}} \mathrm{As}_{\mathrm{x}}\right) \mathrm{S}_{5} \mathrm{I}$ mixed crystals.

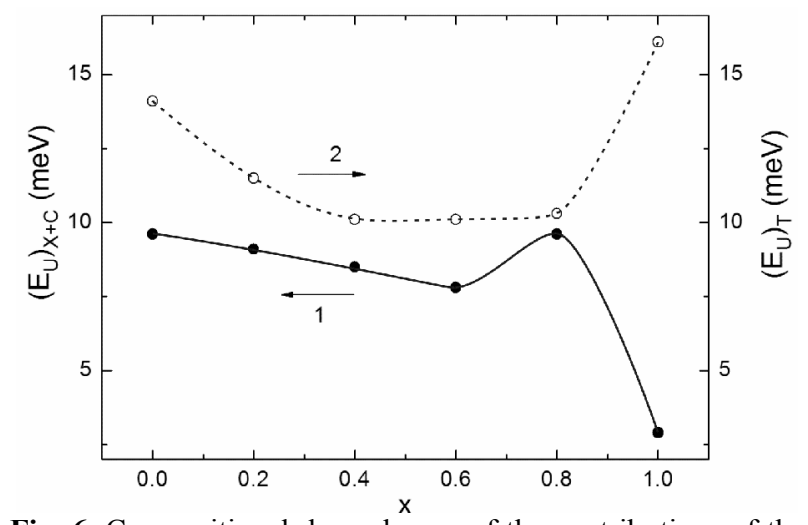

Fig. 6. Compositional dependences of the contributions of the temperature-independent $\left(E_{\mathrm{U}}\right)_{X, C}(1)$ and temperaturedependent $\left(E_{\mathrm{U}}\right)_{T}(2)$ types of disordering for $\mathrm{Cu}_{6}\left(\mathrm{P}_{1-\mathrm{x}} \mathrm{As}_{\mathrm{x}}\right) \mathrm{S}_{5} \mathrm{I}$ mixed crystals.

\section{Conclusions}

Due to the temperature isoabsorption studies, the PT temperatures were determined as well as the $x, T$ diagram was constructed, the last one contains two lines of the first-oder and the second-order PTs. Increase in the As atoms content in $\mathrm{Cu}_{6}\left(\mathrm{P}_{1-\mathrm{x}} \mathrm{As}_{\mathrm{X}}\right) \mathrm{S}_{5} \mathrm{I}$ mixed crystals leads to the monotonous increase of PT temperatures, however, small peculiarity at $x=0.8$ is observed.

The Urbach absorption edge is observed within the temperature interval 77 to $320 \mathrm{~K}$ and is related to the exciton-phonon interaction which is weak for $\mathrm{Cu}_{6}\left(\mathrm{P}_{1-\mathrm{X}} \mathrm{As}_{\mathrm{X}}\right) \mathrm{S}_{5} \mathrm{I}$ mixed crystals. It is shown that the cation $\mathrm{P} \rightarrow$ As substitution leads to the weakening of the exciton-phonon interaction in $\mathrm{Cu}_{6}\left(\mathrm{P}_{1-\mathrm{x}} \mathrm{As}_{\mathrm{X}}\right) \mathrm{S}_{5} \mathrm{I}$ mixed crystals. Temperature dependences of these parameters of the Urbach absorption edge as the optical pseudogap $E_{g}^{*}$ and Urbach energy $E_{\mathrm{U}}$ are well described within the framework of the Einstein model.
Nonlinear decrease in the optical pseudogap in $\mathrm{Cu}_{6}\left(\mathrm{P}_{1-\mathrm{x}} \mathrm{As}_{\mathrm{x}}\right) \mathrm{S}_{5} \mathrm{I}$ mixed crystals at $\mathrm{P} \rightarrow \mathrm{As}$ cation substitution is revealed, while the Urbach energy has the tendency to decrease, however, the character of compositional behavior in this case is more complicated, because the small peculiarity at $x=0.8$ is observed. The Urbach energy in $\mathrm{Cu}_{6}\left(\mathrm{P}_{1-\mathrm{x}} \mathrm{As}_{\mathrm{x}}\right) \mathrm{S}_{5} \mathrm{I}$ mixed crystals is shown to be determined by the effect of the temperature, structural and compositional disordering. The contributions of the temperature-independent (i.e. structural and compositional) and temperature-dependent disordering to the Urbach energy were estimated.

\section{References}

1. W.F. Kuhs, R. Nitsche, K. Scheunemann, Vapour growth and lattice data of new compounds with icosahedral structure of the type $\mathrm{Cu}_{6} \mathrm{PS}_{5} \mathrm{Hal}(\mathrm{Hal}=$ $\mathrm{Cl}, \mathrm{Br}, \mathrm{I}) / /$ Mater. Res. Bull. 11, p. 1115-1124 (1976).

2. W.F. Kuhs, R. Nitsche, K. Scheunemann, The argyrodites - a new family of the tetrahedrally close-packed srtuctures // Mater. Res. Bull. 14, p. 241-248 (1979).

3. T. Nilges, A. Pfitzner, A structural differentiation of quaternary copper argirodites: Structure - property relations of high temperature ion conductors // Z. Kristallogr. 220, p. 281-294 (2005).

4. I.P. Studenyak, M. Kranjčec, Disordering Effects in Superionic Conductors with Argyrodite Structure. Publ. House "Hoverla", Uzhhorod, 2006 (in Ukrainian).

5. I.P. Studenyak, V.O. Stefanovich, M. Kranjčec, Yu.M. Azhnyuk, Gy.Sh. Kovacs, V.V. Panko, Raman scattering studies of $\mathrm{Cu}_{6} \mathrm{PS}_{5} \mathrm{Hal}(\mathrm{Hal}=\mathrm{Cl}$, $\mathrm{Br}, \mathrm{I})$ fast-ion conductors // Solid State Ionics, 95, p. 221-225 (1997).

6. A. Gagor, A. Pietraszko, D. Kaynts, Diffusion paths formation for $\mathrm{Cu}$ ions in superionic $\mathrm{Cu}_{6} \mathrm{PS}_{5} \mathrm{I}$ single crystals studied in terms of structural phase transition // J. Solid State Chem. 178, p. 3366-3375 (2005).

7. I.P. Studenyak, M. Kranjčec, Gy.S. Kovacs, V.V. Panko, I.D. Desnica, A.G. Slivka, P.P. Guranich, The effect of temperature and pressure on the optical absorption edge in $\mathrm{Cu}_{6} \mathrm{PS}_{5} \mathrm{X}(\mathrm{X}=\mathrm{Cl}, \mathrm{Br}, \mathrm{I})$ crystals // J. Phys. Chem. Solids, 60, p. 1897-1904 (1999).

8. I.P. Studenyak, M. Kranjčec, M.V. Kurik, Urbach rule and disordering processes in $\mathrm{Cu}_{6} \mathrm{P}\left(\mathrm{S}_{1-\mathrm{x}} \mathrm{Se}_{\mathrm{x}}\right)_{5} \mathrm{Br}_{1-\mathrm{y}} \mathrm{I}_{\mathrm{y}}$ superionic conductors // J. Phys. Chem. Solids, 67, p. 807-817 (2006).

9. I.P. Studenyak, M.I. Kayla, M. Kranjčec, O.P. Kokhan, and Yu.V. Minets, Isoabsorption and spectrometric studies of optical absorption edge in $\mathrm{Cu}_{6} \mathrm{AsS}_{5} \mathrm{I}$ superionic crystal // J. Phys. Chem. 72, p. 1419-1422 (2011). 
10. A.F. Orliukas, A. Kezionis, E. Kazakevicius, T. Salkus, M.I. Kayla, M. Kranjčec, I.P. Studenyak, Electrical conductivity of superionic composites based on $\mathrm{Cu}_{6} \mathrm{P}_{1-\mathrm{x}} \mathrm{As}_{\mathrm{x}} \mathrm{S}_{5} \mathrm{I}$ solutions // Solid State Ionics, 2013 (to be published).

11. I.P. Studenyak, M. Kranjčec, Gy.Sh. Kovacs, V.V. Panko, V.V. Mitrovcij, O.A. Mikajlo, Structural disordering studies in $\mathrm{Cu}_{6+\delta} \mathrm{PS}_{5} \mathrm{I}$ single crystals // Mat. Sci. \& Eng. B97, p. 34-38 (2003).

12. F. Urbach, The long-wavelength edge of photographic sensitivity and electronic absorption of solids // Phys. Rev. 92, p. 1324-1326 (1953).
13. M.V. Kurik, Urbach rule (Review) // Phys. Status Solidi (a), 8, p. 9-30 (1971).

14. M. Beaudoin, A.J.G. DeVries, S.R. Johnson, H. Laman, T. Tiedje, Optical absorption edge of semi-insulating GaAs and $\mathrm{InP}$ at high temperatures // Appl. Phys. Lett. 70, p. 3540-3542 (1997).

15. Z. Yang, K.P. Homewood, M.S. Finney, M.A. Harry, K.J. Reeson, Optical absorption study of ion beam synthesized polycrystalline semiconducting $\mathrm{FeSi}_{2} / /$ J. Appl. Phys. 78, p. 1958-1963 (1995).

16. G.D. Cody, T. Tiedje, B. Abeles, B. Brooks, Y. Goldstein, Disorder and the optical-absorption edge of hydrogenated amorphus silicon // Phys. Rev. Lett. 47, p. 1480-1483 (1981). 